\title{
AN ANALYSIS OF MCDONALD'S CORPORATION FROM MODERNIST AND POSTMODERNIST PERSPECTIVES
}

\author{
Soleman Mozammel \\ Arab Open University, Bahrain \\ E-mail: smozammel@hotmail.com
}

Article History: Received on $25^{\text {th }}$ February 2019, Revised on $28^{\text {th }}$ March 2019, Published on $25^{\text {th }}$ August 2019

\begin{abstract}
Purpose: The purpose of the paper is to investigate McDonald's Corporation and its social structure, environmental influence as well as it's relationship between the modernist and postmodernist perspectives. The study attempted to discuss both the modernist and postmodernist perspectives as well as examined McDonald's Corporation's various technological innovation of food assembly to draw conclusions.
\end{abstract}

Design/Methodology/Approach: Data was collected mainly through literature review on both modernist and postmodernist theory in order to understand the complexity of organizational culture, operation and leadership followed by linking them with the management of McDonald's Corporation. McDonald's Corporation was chosen due to its global recognition and their management, marketing style along with profit and financial analysis that have been relevant to both scholars and practitioners.

Results: The result have supported and with a conclusion that McDonald's Corporation, like other large organizations follows modernist approach in order to secure their efficiency in production and administration, but at the same time their marketing approach is more of a postmodernist in relations to their cuisine, hyper-reality in franchised restaurant.

Originality/Value: The current study is based mainly on modernist and postmodernist perspectives theories as well as secondary data collection from annual reports and peer reviewed scholarly articles of McDonald's Corporation.

Key words: McDonaldization, modernist, postmodernist, social structure and design, culture, franchising, organizational theory, leader, leadership role.

\section{INTRODUCTION}

An organization may be defined as a complex but open social system that is capable of adapting and coping to survive and prosper in a continuously changing environment (popular press). Based on the definition it can be illustrated that the value of the organizational productivity lies in the satisfaction of its employees, customers, shareholders and stakeholders, respectively. According to Hatch (2006) the complexity relates to the variety of inter-reliant apparatuses such as, organizational design, people, culture, types of leadership behavior and human resources policies and practices that are continuously practiced in the process of mutual adaptation and satisfying each other. Therefore, it is very important to define and understand organizational management as a whole within the boundary of the perspectives prior to relating them with the tools to success such as leadership and motivation.

The structure of the organization is dependent on the types of perspective view of organization theory (OT) the leader believes. The organizational theories are expressed differently in the modernist, symbolic interpretive and the postmodernist perspectives by various theorists over the years. In this paper, the author will discuss and elaborate two perspectives in relation to an organization of choice. Therefore, McDonald's Corporation, the largest franchised fast food restaurant chains in the world, has been chosen for the research. In this paper, the author will analyze McDonald's Corporation (MCD) from both modernist and postmodernist perspectives in the area of management style that includes the production and consumption as well as marketing, culture and hyper-reality of the organization. It is easy for both scholars and practitioners to see the application of the modernist approach in the management of MCD in relation to leadership and motivation since many large organizations follow the standardized structure and routine. But at the same time in the present era, the applications of both symbolic interpretive and postmodernist applications are also existent. Therefore, the purpose of this paper is to investigate the existent of both modernist and postmodernist approach in the management of MCD in terms its social structure, environmental influence and culture that is also known as "McDonaldization of society" (Kellner, 2010; Qoqiauri and Qoqiauri, 2017; Rahim et al., 2018).

\section{Rationale behind choosing McDonald's Corporation (MCD)}

Being a food lover, the author chooses McDonald's Corporations since it is globally recognized and their management style, business system and profit and financial analysis have been relevant studies both for scholars and practitioners for years. The brief introduction of the two famous food industries is given below:

\section{McDonald's Corporation, NYSE: MCD.}

The "great" history of McDonald's was written back in 1940. Their introduction of the "speedee service system" in 1948 founded the ideologies of the contemporary fast food industry. McDonald's filed for the U.S. trademark on the name McDonald's on May 4, 1961 with the description "Drive-In restaurant Services". 
Table 1: Profile at a glance (MCD source)

\begin{tabular}{|l|l|}
\hline Type and Trade & Public and traded as MCD in NYSE \\
\hline Industry/sector & Restaurant/retailing: fast food/ customer service \\
\hline Headquarter/number of locations & Oak Brook, Illinois, USA/ 32000+ worldwide \\
\hline Products & Fast food \\
\hline Market capital & $\$ 71153$ million \\
\hline Employees & 400,000 (January, 2010) \\
\hline Revenue & $\$ 24.075$ billion $+(2010)$ \\
\hline
\end{tabular}

Source: McDonald's Corporation, 2010.

\section{FAST FOOD INDUSTRY}

Today, McDonald's remains one of the major fast food chains in terms of annual revenue in the USA. Their worldwide revenue generated over $\$ 25$ billion in 2010. Approximately 7\% of the entire North American population consume a meal from McDonald's each day resulting in $80 \%$ of American eating at a McDonald's each year. The restaurant offers products that are very homogeneous that is not only limited within their cuisine, but also evident in their menu, uniforms, and architectural style that is a large element of the value coming from being an important member of a fast food chain. The homogeneity is enforced by their founders and therefore, it largely attributed to the vigilance toward the success of McDonald's Corporation.

Although McDonald's Corporation operates some outlets directly, it operates majority outlets through its franchises. Therefore, franchisees pay a fixed franchise tariff along with a percentage of incomes by operating as independent business(es) within the skeleton of McDonald's Corporation, to the franchisor. The franchisees also conduct their purchases from approved suppliers and set prices according under the franchisor's pricing decision.

In the light of the above, it can be concluded that the paper is not only about the fast food industry, but also is subject to franchising industry.

\section{McDonald's Restaurant: Corporation vs. Franchise}

McDonald's eateries are situated over 119 countries globally. It serves approximately 58 million customers a day. The firm has over 1.5 million employees in over 32000 restaurants worldwide. McDonald's offers various types of restaurants offering both "at the counter" and "drive-through" service as well as both indoor and outdoor seating facilities. The drive through facility is only existent in North America, and the outdoor facility is mainly available in a limited number of restaurants.

\section{Modernism and Postmodernism: Perspectives}

\section{Assumptions:}

The definition of ontology and epistemology prior to discussing the perspectives as the theories is rooted in the said views.

- Ontology: implies to the learning of nature of existence of something and its nature, or being. It answers to the query, "what". According to Hatch (2006) ontology concerns our assumptions about reality. The ontological assumptions debate between the reality and the illusion of variables such as culture, power and control from both subjective and objective views.

- Epistemology: is contemplated as the theoretical comprehension in which the existence of something is known. It answers the question "how". According to Hatch (2006) since epistemology is concerned with how things are known, it also relates to questions asked by researchers and practitioners such as, how do humans generate knowledge, and what is the criterion. There is a positivist view that related to discovery about what truly happened in the organization through categorization and scientific measurement of the behavior of employees.

The types of organizational theory perspectives: Rationale for using modernist and postmodernist perspectives.

Since organization is defined as the complex social system, it is inevitable that there are many theorists behind the complexity (Hatch, 2006; Ramuhulu and Chiranga, 2018; Razak, 2018). Therefore, the perspectives of theories are divided into three categories that are presented by Hatch (2006) as modernist, symbolic-interpretive (SI), and postmodernist. The organizational theories are categorized mainly within the boundary of these perspective views. In this discussion only modernist and postmodernist perspectives will be examined in the case of McDonald's Corporation as the author feels these two perspectives have more influence on various aspects of management such as operation, culture and leadership.

\section{Comparison between modern and postmodern perspectives: Positivists vs. Subjectivists}

Modernist approach: Modern science is one of the main aspects of the modernist project. The social science in this context promotes the understanding and the use of science to improve the modern society. Hatch (2006) posited that the 
modernist perspective emphasizes organization as an independent objective entity that relies on positivist approach to producing knowledge. Modernist organization theorists only emphasize on increasing efficiency, effectiveness, and other key performance indicators by applying theories relating to both structure and control. In the light of the above, it can be concluded that the modernist approach commands with objectivism as its ontology, because it believes in the existence of meaning and value in the world (popular press). At the same time it also commands with positivism, because the knowledge under this view is gathered from direct observation and analysis instead of any abstract reasoning (Popular press). Starbuck (2005) described modernist approach as positivism. According to Starbuck (2005) the adaptation of the organization to its current environment allows it to perform more highly. The question remains to be answered as how much adaptability does the leader within modernist approach can command within the present socio cultural situation. According to Esade and McKelvey (2010) modernism and its methodological hand-maiden, positivism, have long underpinned the epistemic legitimacy of the natural sciences.

The organization under the modernist view consists of a set of individual management set up with processes and objects that distinguish the organization in the external environment. Modernist view focuses on organizational theories using universal laws, methods and techniques of organization and control as well as it favors the rationale structures, rules, and standardized procedures. Therefore, under this system, the organization is a real entity operating in the real world with a well-designed and managed leadership with effectiveness (Weatherly, 2010).

Since the birth of division of labor during the industrial revolution, organizations focused on production efficiency (Hatch, 2006). The modernist approach toward the scientific method of division of labor and systematic leadership approach suited well in the industrialized world with the focus of operating and manufacturing efficiency. In the present era, in many developing countries that are dominated by small firms have the culture of modernist view in relation to running management effectively. Management bureaucracy also plays an important role in the modernist approach, Starbuck (2005)

Postmodernist approach: The postmodernism generates skepticism toward any other dominant theories and goes hand in hand with changes according to time (Hatch, 2006). Some of the key qualities such as subjectivity, deconstruction, discourse and interpretation are evident in this theory. According to Hatch (2006) postmodernists advocate radical change via deconstruction as well as keeping a "strong ethical tinge" under the stakeholder theory. According to Esade and McKelvey (2010) "the postmodernist epistemology is profligate rather than parsimonious by entertaining multiple representations of phenomena as equally valid alternatives." Under this theory the world appears through language and discourse. Knowledge is not necessarily the accurate measure of truth as the meaning cannot be limited to one (Esade and McKelvey, 2010). This theory does not believe in any independent reality but only believes in interpretation of views that defines knowledge as power play.

Table 2: Comparison Summary of modernist and postmodernist methodological approaches

\begin{tabular}{|l|l|}
\hline Modernism & Postmodernism \\
\hline $\begin{array}{l}\text { Ontology: Believe in an objective and external reality } \\
\text { where knowledge is gained in limited five senses and is } \\
\text { confirmed through repetition of procedures. }\end{array}$ & $\begin{array}{l}\text { Ontology: Believes in the continuous process of learning } \\
\text { and performing through the different alternatives. }\end{array}$ \\
\hline $\begin{array}{l}\text { Epistemology: Positivism - the truth is conceptualized } \\
\text { and a reliable measurement process that allows testing } \\
\text { knowledge against an objective world followed by } \\
\text { allowing humans to progress and evolve }\end{array}$ & $\begin{array}{l}\text { Epistemology: postmodernism- Knowledge is limitless, } \\
\text { therefore cannot be an accurate account of truth as } \\
\text { meanings can be interpreted differently instead of being } \\
\text { fixed. Knowledge is a power play in this case. }\end{array}$ \\
\hline $\begin{array}{l}\text { Organizations are real entities, when well-organized } \\
\text { and managed they are systems of decision making } \\
\text { focused mainly on efficiency and effective performance. }\end{array}$ & $\begin{array}{l}\text { Organizations are sites of enacting power relations, } \\
\text { oppression, irrationality, communication distortion or } \\
\text { arenas for fun and playfulness. }\end{array}$ \\
\hline $\begin{array}{l}\text { Focus: Finding universal laws, methods and techniques } \\
\text { or organization and control: rational structures, rules } \\
\text { and standard procedures }\end{array}$ & $\begin{array}{l}\text { Focus: Deconstructing organizational texts; destabilizing } \\
\text { managerial ideologies and modernist modes of organizing } \\
\text { and theorizing; revealing marginalized and oppressed } \\
\text { viewpoints; encouraging reflexive and inclusive forms of } \\
\text { theorizing and organizing. }\end{array}$ \\
\hline $\begin{array}{l}\text { Example: Taylorism vs. Empowerment: Time and } \\
\text { motion studies for control, empowerment of the } \\
\text { individual on the spot }\end{array}$ & $\begin{array}{l}\text { Example: Calculation can lessen empowerment- rational } \\
\text { analysis is a part of empowerment as well as courage, } \\
\text { judgment, aesthetics, and trust. }\end{array}$ \\
\hline
\end{tabular}

Note: Adapted from Hatch (2006).

Table 1 clearly states the comparison in methodology between modernist and postmodernist approaches. The perspectives also impact the organization in terms of other variables such as design, and culture that are discussed in this paper.

The Impact of Perspectives on Organizational Design and Management 
The perspectives have significant effect on organization in terms of its design, and management that also deals with internal and external environment, social structure, organizational culture and technology. Therefore, in order to motivate employees, there is a need of a suitable leadership that fit the criteria of the organization in relation to the perspectives. The author will illustrate the comparison between the perspectives keeping the modernist theory as the main.

\section{Social Structure and Culture: Risk, Uncertainty and Effective Resource Allocation}

Organizational culture (OC) may be defined as an idea in the field of organizational theory and management that expresses the psychology, attitudes, experiences, beliefs and values gathered from the human behavior of the organization. According to Hatch (2006) modernists believe that suppositions and values impact behavior by expressing their norms and values, whereas culture is connected through artifacts such as stories, tradition or customs. On the other hand, postmodernists contest the notion of organizational cultures through polyphony theory and intertextuality suggesting the shared understanding of an organizational culture to be an illusion only.

Risk is defined as the potential that result in a loss due to a chosen action or activity. Risk can also be defined as the effect of uncertainty (Popular Press). For example, having a new CEO on board, the potential risk may be the underperformance or not getting along with the team. On the other hand, uncertainty is the term applied to prediction of future events with the measurement of the outcome already made. Therefore, uncertainty has more than one outcome. The same example of the new CEO can be used with either performance or under performance.

In the light of the above, the question of effective resource allocation is determined. According to Arndt (2010) the development and sustainability of competitive advantage of a firm is the fundamental question of strategic management. The discussion of dynamic capabilities has emerged out of the resource-based view that characterizes the firm as a bundle of resources. Therefore, it is relevant to say that there is an important relationship between the entrepreneurial and the environment school as the former involves leadership that requires the dynamic capabilities to adapt to the effect of the changes in the latter and take action accordingly. Arndt (2010) addresses dynamic capabilities with three components such as,

- The ability to monitor and sense the changing environmental demands and emerging opportunities in new markets and technologies.

- The ability to analyze new information through a variety of channels in order to seize opportunities and threats.

- The ability of managers to apply necessary organizational and inter-organizational changes for the firm as well as responding to new opportunities, while neutralizing the threats.

The modernist approach with both objectivism and positivism settles in with the type of leadership that belongs to the strategic school of both "entrepreneurial and environment school of thought" (Mintzberg's, 1998).

The postmodernist view opposed to the modernist in some extent, as the primary looks at leadership and management in the form of group discussion based on the condition of its employee group. At the same time, the postmodernist view literally does not believe in any of the logic of modernist view as it deconstruct according to the change of the social structure. According to Hatch (2006) postmodernists focus on structural thinking by eliminating bureaucracy. Based on that, it can be assumed that postmodernist perspective does not allow rationality, calculation, and control that increase efficiency limiting diversity, creativity and free will. On the other hand, postmodernism believes in transformational leadership that is more suitable for diversity, creativity and free will and does not match with "entrepreneurial and environment school of thought" (Mintzberg's, 1998).

\section{Fast moving environment}

In the fast moving environments, if the situation gets turbulent, traditional hierarchy structures constrain implementation; therefore, cross-functional process oriented structure may be essential. According to Cravens et al. (2009) an emphasis on shifting towards innovation, pro-activeness and risk taking is essential while responding to various challenges such as innovation, and speed that are requirements of today's strategic change initiatives. The fast moving environment often contributes to the challenges towards development of conceptual logic for strategic thinking in today's rapidly changing environment. Leadership is an integral tool in strategic management, as the leader needs to have the capacity to understand the fast changing environment and take initiatives accordingly.

Modernist approaches have a clear vision about leadership and hierarchy when it comes to the subject of organizational part and environmental part. The modernist view uses a differential method by initializing strategy, decision making and production. The main view of modernist is that a strategic management provides a link between the organization and its environment through which information and influence pass (Weatherly, 2010).

Postmodernist approach sees the environment as thinking without boundary. Some of the key qualities such as subjectivity, deconstruction, discourse, and interpretation are evident in this theory (Hatch, 2006). According to Hatch (2006) postmodernists advocate radical change via deconstruction as well as keeping a "strong ethical tinge" under the stakeholder theory. Although there may be disagreement between stakeholders' interests against that of shareholders' the primary plays a stronger role in the deconstruction. According to Freeman (as cited) in Hatch (2006) legal interpretations 
of corporate responsibility are restricted due to protecting and enhancing shareholder wealth, but not at the expense of not fulfilling the ethical duties. Therefore, it is evident that any organization that is operated within the modernist frame is also under the pressure of postmodernist approach regarding their duties toward humanity.

\section{ROLE OF A LEADER AND STRATEGY DEVELOPMENT}

Developing and re-establishing a strong strategy is often a big challenge and requires leadership. Confusion may arise due to large variation in work forces in relation to making choices and trade-offs in organizations; therefore, leadership is a necessity to guide a strategy by using an intellectual framework. According to Porter (1996) although a leader has generated improvement in operations and making deals, he plays a broader as well as a more important role to keep the general management as a core strategy defining, communicating and forging the organizational position, its uniqueness, trade-offs and fitness among activities. Such leadership must deliver the discipline to select the notion of environmental changes that include changes in industry, its customer needs and demand that the organization responds to. At the same time, the organization must avoid any distractions caused by the changes and maintain singularity. Porter (1996) argues that improvement of effectiveness in operation is an essential part of organization, though it is not strategy. Therefore, leaders must make their managers understand the distinguished meaning effectiveness from strategy.

Based on the above, it can be concluded that in order to evaluate risk, uncertainty, managing the allocation of effective resources, understanding the influence of market structure in developing strategy as well as facing the fast moving environmental changes, organization requires leaders with vision who can implement strategy as a response to the challenges imposed by the external environment. Modernist view on strategy is an act of leadership and the leader's hierarchy that is passed down through to the organization for the implementation for the employees. On the other hand, strategy is an act of different interpretation and cognition that frame every aspect of strategy development by the leader in SI. Leadership is a form of communication and discussion, therefore, transformational. The postmodernist view on strategy development is beyond any limitation of thoughts therefore, it is temporary, incomplete and self-organized as opposed to natural or social selection (Hatch, 2006). It comprises of a dynamic change within the organization, where system changes occur through recalculation, re-invention and modification of the organization resulting in adaptation, survival, growth and development.

\section{ANALYSIS OF MCDONALD'S (MCD) FROM MODERN AND POSTMODERN PERSPECTIVES}

\section{McDonald's (MCD) Between the Modern and Postmodern:}

According to standard explanation, the management of MCD is considered to be modernist, but at the same time (Ritzer, 1993) argues MCD to be more postmodernist. The explanation or industrial development of food assembly establishes disagreement with traditional objects everyday life and death that includes agricultural mechanism, food labor, and house cleaning. Therefore, according to Ritzer (1993) growing rationalization of daily life disagreements with traditional that substitute with "modern" forms, create conflict between the modern and the pre-modern resulting in claiming MCD to be more postmodernist that also created the new cultural form called, "McDonaldization". However, Kellner (2010) argues that the existent of both modernist and postmodernist perspectives are existent in McDoanldization. He also states that McDonaldization as an explanation of both assembly and consumption is clearly modern in inspiration and practice like any other large standardized organization. On the other hand, the proliferation of sign value in the MCD experience through advertisement and publicity stunts offer postmodern complications as its customers enter quasi-mythical hyperrealist world of American life portraying family, fun, and good times.

Therefore, McDonaldization was pre-eminently an expression of modernism. The mass production and consumption of food crossed the postmodernism division through advertisement and product manifestation, stretching its customers into a world of simulation, hype- reality and the implosion of cross-country boundaries as a global organization and being a part of postmodern hybridization that synthesizes signs of modernity with local tradition and culture. Therefore, Kellner (2010) argues that McDonaldization is combination of both modernism and postmodernism which he later also defined as "multiperspective." According to Kellner (2010) McDonaldization relates not only to both Weber's analysis of rationalization and Marx's theory of commoditization, but also postmodern conceptions are involved in it. Therefore, implosion, hyperreality and simulation as well as analyses of post-Fordist globalization, the hybridization of identity and semiotic practices that are central elements of postmodernism condition (Boje, 2006) are visible within the context of McDonaldization.

Cuisine: According to Kellner (2010) postmodernism is evident within the McDonald's cuisine as a simulation of food due to its artificial foodstuffs, tastes, and pleasures that simulate such familiar products like burgers, fries, and shakes. Since the foodstuffs are heavily reliant on chemical extracts and artificial ingredients for their flavor, texture, and materiality, MCD products establish a technological model of fast food assembly and consumption. It also re-forms food itself by using a unique food technology to produce innovative ingredients, tastes, and substitutions and, therefore, the artificial techno-foods for the future (Kellner, 2010).

Hyper-real: The fast food model of MCD substitutes the old-style culture of home-prepared food with commoditized food. It has become a model for food assembly that replicated through frozen and organized food and the spinoff of numerous other chain fast food restaurant businesses. Therefore, MCD delivers a new hyper-real model of food and 
eating, facilitated by its food technologies and organization of food assembly and consumption. At the same time, the advertising and promotion enables MCD customers to join in to the hyper-real philosophies of Americana and family togetherness and social bonding.

Global: Although MCD signify Western modernity, at the same time it adapts to the local culture and cuisine. For example, serving noodle dishes in Asian countries, or naming Big Mac as "Maharajah" mutton burger instead of serving beef burger in India, respecting their religious value in eating beef. MCD helps standardize and homogenize a global consumer culture as well as brings variety, diversity, and novelty to many parts of the world contributing to the creation of a hybridized postmodern global popular.

Therefore, it is evident that both modern and postmodern perspectives are evident in McDonaldization. In order to analyze the phenomenon, it is important to focus on both production and consumption that involves the modernism as well the postmodern cultural dimension of hyper-real and hybridized consumption.

\section{Organizational Culture: the McDonaldization of Society:}

McDonald's Corporation (MCD) is known to be a role model of both being a production and consumption based organization. According to Ritzer (1993) the phenomenon of "McDonaldization" encompassed both assembly and consumption as well as raised to a broad scope of economic, political, social and cultural artifacts and mechanisms. The question raised whether McDonaldization is properly a phenomenon of modernist or postmodernist perspective, or whether it is simply a modern or postmodern theory. According to Kellner (2010) MCD's fast food eateries offer a sample of accustomed sociological artifact that is analyzed to generate more general and macro level of conceptualization. The Big Macs, Golden Arches, Ronald McDonald's promotional tie-ins with popular films and toys, its charities, and saturation advertising are symbols of MCD's status called "McDonaldization of society" that is enjoyed by very few organizations in the world.

"McDonaldization of society" symbolizes maximized efficiency, calculability, predictability and control through substitution of human labor power with technology that constitute a quantitative and to some alarming growth of influential justification (Kellner, 2010). According to Ritzer (1993) the concept of McDonaldization of society has conquered and dominated many sectors of American society as well as the rest of the world. The theory of McDonaldization can be a synthesis of the theory of Marx/Weber that is a combination of instrumental explanation of assembly and consumption with a sustainable corporate attempt to maximize profit. Therefore, the theory of McDonaldization symbolizes a new global form of techno-capitalism in which world markets are being rationalized ad reorganized to maximize capital accumulation.

The cultural dimensions of McDonald's are also striking with their advertising campaigns, and promotional stunts to create an experience of fun, of family togetherness and of Americanization. The main theme behind McDonald's involves an experience of good times, communal experience and consumer value when one bites a Big Mac.

The ideology of McDonaldization is a set of social practices, a cultural construct with its myths, semiotic codes, and discourses (Kellner, 2010). It symbolizes a model of the USA as a land of customer innovation and technical prudence that produces inexpensive and desirable goods for all races, serving its customer's needs and providing a valuable product. MCD associates itself with traditions such as family, national holidays, patriotism, charities and icons of media culture.

Therefore, MCD is an ideological and cultural phenomenon as well as an economic and sociological set of practices.

\section{Conflict between modernist and postmodernist approach}

Conflict management involves implementing strategies to limit negative aspects of conflict and to increase the positive aspects of conflict at a level equal to or higher than where the conflict is taking place (Popular press).

The management of McDonald's is divided into two main categories such as administration and marketing. The administrative structure is very mechanistic, therefore it is considered modernist. According to Hatch (2006) modernist theory favors standardization, structure, and routine, therefore, objectivism and positivism epistemology plays an important role in it. The mechanistic system is also hierarchical and highly centralized and commands with well-defined formalized job description (Hatch, 2006; Razak et al., 2018; Rekik, 2018; Riaz and Riaz, 2018). According to Starbuck (2005) the mechanistic system is often compared to machine, consisting of specialized parts; therefore, people in the system are more "robotic" and command with a uniformed behavior. The administration of MCD is very formalized and mechanistic under the modernist theory.

On the other hand, the marketing division of McDonald's is more based on the postmodernist perspective; therefore, it is part of the organic system. According to Hatch (2006) the organic system is flexible and adaptive toward continual changes within the environment, and promotes the exchange of information accordingly. The recent advertisement campaign of McDonald's for promoting breakfast includes "great morning" instead of traditional "good morning" (McDonald's source), which is the example of organic system with flexibility. Customer service and customer satisfaction requires flexibility (popular press). Starbuck (2005) stated that decentralized and innovative approach under the organic system is designed for adjustments and bringing variations to the management. 
Based on the above discussion, it can be addressed that despite the conflict between the theories, MCD as a whole, is using both perspectives in their respective divisions. Therefore, the positivism epistemology is evident through the mechanistic organizational management where the jobs are more standardized and "robotic" whereas the accomplishment of task is represented by the subjectivism ontology that represents employees and the relationship between employees and customers. Therefore, the organization has taken full advantage of the intra-organizational conflict that is evident between the two managerial departments. The conflict between the two departments is resolved by setting different goals. The administrative department is responsible for variables such as monitoring working condition, the production and consumption, cost and profit; whereas the marketing department is mainly concerned with customer satisfaction, and promotion of the organization according to the environmental changes. Therefore, both divisions of MCD are running smoothly.

\section{Organizational elements contributing to the effectiveness of McDonald's}

The uniqueness of overall management of McDonald's is the key to their effectiveness. The company managed to demonstrate superior decision making in the brand management that distinguish them from competitors. The company does not have any short term profit goal. Rather it commands with a long term objectives that include training their managers in the form of "duplication" (McDonald's Source). All the managers of the stores believe in the unique traditional philosophy of customer service excellence.

Technology innovation is another reason McDonald's has an advantage over competitors. According to Kellner (2010) McDonald's provides fast food that replaces the traditional model of home-prepared food with commoditized food. The technology of processing food fast and serving large number of customers within a short period of time is the key to customer satisfaction. The invention of "drive thru" is another successful innovative idea of MCD.

Training and developing workforce is another key success element of MCD. The organization has developed its own university for managers. McDonald's remain to be the only food industry to own a university for employee development (McDonald's source). Therefore, the employee growth is based on the McDonald's philosophy. At the same time, employees are also accountable for the quality of their work. The motivation of the employee is enhanced as workers are aware about possibility of climbing the ladder to become either manager, or shareholder of the company irrespective of where they start at. Like many other large organizations MCD also has incentives and reward program for employees such as ESOP (employee share option program) and performance rewards. Therefore, the postmodernism is evident in relation to employee motivation.

Most large firms in consumer markets own and promote more than one brand.

\section{Prognosis for successful continuance of the organization}

Being the largest fast food industry, McDonald's is always at the threshold of being criticized for promoting unhealthy diet with usage of preservatives and frozen raw materials. At the same time, the other ethical issues such as low wages, advertising practices, involvement in deforestation, harvesting of animals also added to the negative publicity of the company. Despite the claims, MCD defends their products to be "balanced diet".

Despite the complaints and the campaigns against MCD, the corporation still leads the fast food industry with their service and market promotion along with usage of effective business model. Adaptability with the environmental and cultural requirement also adds to the success of the organization. The success of the company lies on the large portion of the consumers the company serves along with the large amount of employment it generates. McDonald's restaurants are situated over 119 countries and territories around the world that serve approximately 58 million customers each day. The firm has over 32000 restaurants worldwide employing over 1.5 million people. McDonald's offers various types of restaurants offering both counter and drive-through service as well as both indoor and outdoor seating facilities. The drive through facility is only existent in North America, and the outdoor facility is mainly available in a limited number of restaurants (McDonald's source).

\section{DISCUSSION/REFLECTION/INSIGHT}

Late modern forms of capitalism kept appropriating ostensibly postmodern moves. According to Boje (2006) managerialisms began to use language of postmodernists to generate models of managing and organizing that were called "postmodern" but offered less than democratic and ecologically unsustainable approaches. In his argument he added MCD beginning to sell salads while advertising its fast food as nutritious, and Wal-Mart wrapped itself in patriotism, and Americana, while intensifying its surplus value sweating of labor in stores and subcontract sweatshops. According to Boje (2006) knowledge management, learning organization, and dialogue consulting offered up "Knowledge workers", "empowerment" and "complexity" models that were part of postmodernism are actually a late modern manifestation of post-bureaucratic, post- Fordist and post-Taylorist forms of surplus value extortion.

In recent years MCD has been making ethical claims through aesthetic-photos and cartoons, and cognitive claims about the science of fast food nutrition, though other nutritionists, fitness experts and culture jammers are opposing their claim. Therefore, it can be argued that McDonaldization that portrays the postmodernism aspect of MCD advertisement is only a 
commercial "propaganda". On the other hand, the modernist aspect that only deals with the management attributes such as production mechanism does not face the same "controversy."

Based on the above discussion, a conclusion may be drawn that all perspectives such as modernist and postmodernist influence the organizational design and social structure in relation to the environment as well as performance effectiveness. The main success of the organization lies on the ability of the leader and therefore it is essential for the employees to know which perspective background the leader is emerging from. The definition of the meaningful leader as described by Ulrich and Ulrich (2010) clearly indicates that "leaders" command with the components of all the schools and adaptive toward any changes. Leadership with vision increases the employee motivation resulting in increasing productivity. The organizational complexity relates to the variety of interdependent tools such as, organizational design, people, culture, leadership behavior and human resources policies and practices that are continuously engaged in the process of mutual adaptation and satisfying each other. Therefore, it is important for leaders to know and understand the OT perspectives build the foundation of the organization accordingly. Example can be drawn from Apple Inc. again with Steve Jobs. Under his leadership, Apple bounced back to the competition with Dell, and has re-established the brand both with product superiority and expectedly outstanding after sales service.

\section{Perspectives related to the author's philosophy}

Based on the study on McDonald's Corporation, the multi perspective of McDonaldization relates closely to the author's personal philosophy. The author is educated in the business studies; therefore McDonald's Corporation remained as a case study throughout the Bachelor and MBA education of the author. At the same time, the author has multiple experiences of being a family business owner that included industry and shipping as well as being a faculty of business and a management consultant. At present, the author works for large organizations in the financial industry. His experiences included the modernist approach in the industry and large organization sector, but at the same time postmodernist perspective also played an important role in his teaching and consultancy career. Therefore, the author totally agrees with the multi perspective approach of McDonaldization as stated by Kellner (2010).

\section{CONCLUSION}

The paper aimed to compare and contrast the theoretical approaches of both modernist and postmodernist perspectives in relation to the organizational culture of McDonald's Corporation. In this paper, the author chose McDonald's Corporation since it is globally recognized, and their management, marketing style along with profit and financial analysis have been relevant studies for both scholars and practitioners. In order to elaborate McDonald's Corporation, the author also addressed the contribution of MCD in the fast food industry as a franchised restaurant. At the same time, the theories of both modernist and postmodernist perspectives were discussed in details in order to understand the complexity of organizational culture, operation and leadership followed by linking them with the management of McDonald's Corporation. Based on the management and marketing analysis on the MCD, it is evident, that MCD, like any other large organization follows modernist approach in order to secure their efficiency in production and administration, but at the same time their marketing approach is postmodernist in relation to their cuisine, hyper-reality in food production using technology, and their global approach by adapting local culture as a franchised restaurant. Therefore, the combination of both modernist and postmodernist perspectives has become the culture of McDonald's Corporation in the name of McDonaldization. Despite receiving negative vibe from critics for producing standardized, unhealthy, non-dietary, junk food for profit, McDonaldization is here to stay. At the same time, the paper also illustrates that McDonaldization from a multi-perspective approach helps scholars and practitioners to understand the current form of contemporary society followed by attempting to create a better one.

\section{REFERENCES}

1. Arndt, F., 2010. Assessing dynamic capabilities: Mintzberg's school of thought. South African Journal of Business Management, 42(1).https://doi.org/10.4102/sajbm.v42i1.484

2. Boje, D.M., 2006. What happened on the way to postmodern? Qualitative Research in Organization and Management Journal, 2006. New Mexico State University.

3. Cravens, D.W., M.J. Neely, N.F. Piercy and A. Baldauf, 2009. Management framework guiding strategic thinking in rapidly changing markets. Journal of Marketing Management, 25(1-2).Available at: 10.1362/02672579x4100025.https://doi.org/10.1362/026725709X410025

4. Esade, M.B. and B. McKelvey, 2010. Integrating modernist and postmodernist perspectives on organizations: A complexity science bridge. Academy of Management Review, 35(3).https://doi.org/10.5465/AMR.2010.51142028

5. Hatch, M.J., 2006. Organizational theory: Modern, symbolic and postmodern perspectives. 2nd Edn., NY: Oxford University Press.

6. Kellner, D., 2010. Theorizing/resisting McDonaldization: A multi perspectivist approach. Available from http://www.gseis.ucla.edu/faculty/kellner/kellner.html.

7. Mintzberg's, 1998. Ten schools of thought about strategy formation, Google source, 2011.

8. Porter, M.E., 1996. What is strategy? Harvard Business Review, November-December, 1996. 
9. Qoqiauri, L. and N. Qoqiauri, 2017. Determining issues of the economic essence and methodology of foresight. In: Quality Management: Search and Solutions. pp: 42-56.

10. Rahim, A.R.A., S. Noranee, A.K. Othman, A. Shabudin and A. Anis, 2018. Organisation restructuring: The influence of interpersonal conflict, anomie, and trust in management on counterproductive work behaviour. International Journal of Management and Sustainability, 7(2): 83-92. https://doi.org/10.18488/journal.11.2018.72.83.92

11. Ramuhulu, M. and N. Chiranga, 2018. An investigation into the causes of failures in railway infrastructure at transnet freight rail-a case of the steel and cement business unit. International Journal of Sustainable Development \& World Policy, 7(1): 8-26.https://doi.org/10.18488/journal.26.2018.71.8.26

12. Razak, A., 2018. Bank incentives for risk-taking; evidence of selected commercial banks in ghana. Asian Journal of Economic Modelling, 6(2): 135-146.https://doi.org/10.18488/journal.8.2018.62.135.146

13. Razak, A., S. Sarpan and R. Ramlan, 2018. Influence of promotion and job satisfaction on employee performance. Journal of Accounting, Business and Finance Research, 3(1): 18-27. https://doi.org/10.20448/2002.31.18.27

14. Rekik, M., 2018. The moderating effect of governance mechanisms on the relationship between innovation strategy and the performance. International Journal of Business, Economics and Management, 5(3): 68-93. https://doi.org/10.18488/journal.62.2018.53.68.93

15. Riaz, N. and S. Riaz, 2018. Investment and economic growth: A panel data analysis. Asian Development Policy Review, 6(1): 20-31.https://doi.org/10.18488/journal.107.2018.61.20.31

16. Ritzer, G., 1993. The McDonaldization of society. Thousand Oaks, Ca: Pine Forge Press.

17. Starbuck, W.H., 2005. The origins of organization theory. In H. Tsoukas, \& C. Knudsen (Eds.) The Oxford handbook of organization theory: Meta-theoretical perspectives. New York: Oxford University Press. pp: $143-$ 182.

18. Ulrich, D. and W. Ulrich, 2010. Leaders who make meaning meaningful. Ivey Business Journal Online. Retrieved October, 31, 2010 from ABI/INFORM Global database.

19. Weatherly, N., 2010. A review of Hatch's "organization theory: Modern, symbolic, and postmodern perspectives. Organization Theory. 